\title{
Editorial
}

\section{Behavioural psychotherapy and the behavioural sciences}

Behavioural psychotherapy is a clinical science to the extent that its results are predictable and repeatable. These criteria are met some of the time though much remains an art waiting to be brought into the scientific domain. Certain treatment principles are now so well established that some sufferers can treat themselves without a therapist merely by using a simple self-help manual (Marks, 1978).

Behavioural psychotherapy draws on concepts from a wide variety of behavioural sciences ranging from the biological to the psychosocial (Marks, 1981 ). The relevance of biology is seen clearly in the biological boundaries of learning, the limits to which stimulus-response associations can be made, and the age at which such associations can appear. This concept has long been embedded in ethology and more recently has spread to learning laboratories. It helps to explain the distribution and timing of certain fears and fetishes but does not affect therapy as yet, since exposure treatment seems to work as well with prepared as with unprepared phobias.

Roots in neurochemistry and psychophysiology are seen in findings about the role of peptides and C.N.S. pathways in the acquisition and extinction of avoidance, pain, placebo and other responses. One form of fear, the tonic immobility reaction (sham death) can be brought under genetic, biochemical and dietary control even though it is a response to the specific stimulus of physical restraint or other sudden intense threat. Psychopharmacology is relevant to selected patients in whom drugs play a role in treatment hand in hand with behavioural methods, e.g. where depression complicates phobias and obsessions, and in schizophrenia, where phenothiazines increase the threshold of breakdown to stressful life events, yet preliminary behavioural research suggests that the impact of such events may be reduced by decreasing the expressed emotion of hostile relatives. Yet another interaction between behavioural psychotherapy and biology is seen in the Lesch-Nyhan syndrome which is a congenital error of metabolism, yet teaching the parents an operant approach has decreased affected children's crippling self-mutilation.

The relevance of psychology to behavioural psychotherapy is evident in the similarity experiments on flooding of avoidance responses bear to exposure treatments of phobias and rituals, in the way operant laboratories have influenced operant treatments, and more recently how research into problemsolving skills shows promise for improving methods of self-regulatory treatment. 
Sociologists' ideas are important for any therapist, e.g. the factors which lead to illness behaviour, the precipitants of initial referral, and the role of social networks in the waxing and waning of many disorders; it is not yet clear to what extent the attenuation of social networks which is seen with many behavioural disorders is their cause or their consequence.

Behavioural psychotherapists who are alert to the problem of long waiting lists of suffering patients with insufficient therapists to help them become aware of problems of yet another discipline, viz. economics and the delivery of behavioural services, given the inevitable constraints on everyone's resources. Linked to these are educational issues on how to train effective therapists at the lowest cost. Important concepts here are those of the minimum care dose for patients and the minimum training dose for therapists.

In deciding curricula to train behavioural psychotherapists, we need to be clear what the training is for. If we are aiming to produce scientific researchers and teachers, then a broad-based education in the behavioural sciences is essential, ranging from the biological to the psychosocial. However, for those who are mainly interested in therapy rather than in actively pursuing research, less of this detailed knowledge is necessary and much more about the clinical skills needed in therapy.

\section{References}

Marks, I. M. (1978). Living with Fear, New York: McGraw-Hill.

Marks, I. M. (1981). Cure and Care of Neuroses, New York: John Wiley.

ISAAC MARKS 